\title{
Study on osteopotential activity of Terminalia arjuna bark extract incorporated bone substitute
}

\author{
G KRITHIGA $^{1}$, T HEMALATHA ${ }^{1}$, R DEEPACHITRA ${ }^{1}$, KAUSIK GHOSH ${ }^{2}$ and T P SASTRY ${ }^{1, *}$ \\ ${ }^{1}$ Bioproducts Laboratory, Central Leather Research Institute, Adyar, Chennai 600 020, India \\ ${ }^{2}$ Footwear Design and Development Institute, International Testing Centre, Irungattukottai 602 105, India
}

MS received 3 June 2013; revised 9 October 2013

\begin{abstract}
Bark extract of Terminalia arjuna (TA) possesses potent medical properties and therefore, holds a reputed position in both Ayurvedic and Unani systems of medicine. Bone substitutes play an inevitable role in traumatic bone damages. Growth factors induce osteoinductivity, but suffer from limitations such as high cost and side effects. This study aims to evaluate the osteoinductive potential of bark extract of TA in bone substitutes. Bone substitutes prepared with TA bark extract were characterized for their physicochemical properties. In vitro biomineralization study was carried out using simulated body fluid. Cytotoxicity, alkaline phosphatase activity and mineralization potential were assessed using MG-63 cell lines. Scanning electron microscope revealed apatite formation on the surface after biomineralization. Thermogravimetric analysis showed $15 \%$ increase in residual weight by deposition of calcium and phosphate and their presence was identified by energy dispersive analysis. Increased alkaline phosphatase and calcium release was observed in bone substitutes prepared with TA extract compared with control. The functional groups of TA bark extract help in in vitro biomineralization. In MG-63 cells, it showed potential influence in cell differentiation. TA extract may be used as low-cost alternative for growth factors for treatment of fractured bones.
\end{abstract}

Keywords. Terminalia arjuna; osteoinductivity; bone substitutes; biomineralization.

\section{Introduction}

Natural products are recognized as an endless source of medicine and have dominated the human pharmacopoeia for thousands of years (Raskin and Ripoll 2004). Alternative medical therapies have become common trend the world over for the past decade owing to their fewer side effects, low costs and increased efficacy (Bussmann and Sharon 2006). In both developed and developing countries, the use of plant-derived products in health care is very common and this incorporates the use of botanical medicines (either alone or in combination with prescribed medicines). Natural products continue to make an impact in new drug discovery, and in recent years the interest has intensified in the field of orthopaedics. Plant active compounds are tested for their bone formation ability in osteoblast cell lines. India is well established as a huge source of medicinal plants, viz. Silybum marianum, Picrosshiza kursoa, Phyllanthus niruri, Terminalia arjuna, etc., in the treatment of bone fracture.

Terminalia arjuna (Roxb.) (TA) is a deciduous tree of combretaceae family widely distributed throughout India. It is well recognized in Ayurveda (Indian traditional

\footnotetext{
*Author for correspondence (sastrytp@hotmail.com)
}

medicine) for its various therapeutic values (Dwivedi 2007). The bark of TA is recommended as cardioprotective agent for hypertension and ischaemic heart diseases (Gauthaman et al 2005; Hemalatha et al 2010). The bark paste of TA is being successfully used for the treatment of fractured bone of animals as well as of humans. It is believed that fractured bones regenerate at a faster rate if the bark paste is used and plastered with the bark itself. In practice, the decoction of the bark is used therapeutically to relieve the pain and inflammation (Patnaik et al 2007).

Bone damages or traumatic events lead to the removal of large portions of bone, creating critical size defects and necessitating bone substitutes to help in regeneration. In the past few decades, application of calcium phosphate ceramics as a bone substitute material is becoming inevitable. Bioactivity is its key factor along with biodegradability and biocompatibility (Ogose et al 2005). In vitro studies proved that only bioactive materials are able to form bone apatite on the surface when placed in simulated body fluids (SBFs). Among the bioactive materials, biphasic-calcium phosphate (BCP) is gaining interest because of its flexibility in changing resorbability by change in ratio of hydroxyapatite and tricalcium phosphate. To impart osteoinductivity to any bone substitute, growth factors like bone morphogenetic proteins are incorporated by different methods. Growth factors are 


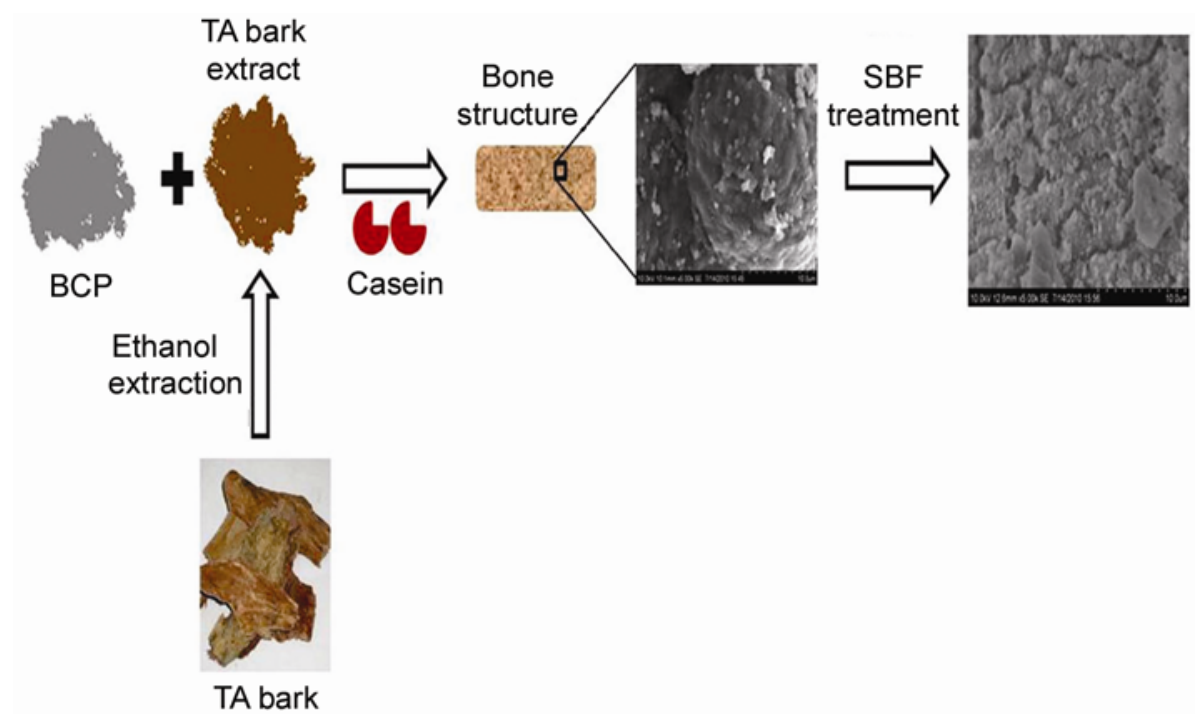

Figure 1. Study on osteopotential activity of Terminalia arjuna bark extract incorporated bone substitute.

degraded easily in vivo and thus requires high quantity to achieve the intended results; moreover, it will lead to side effects, including cancer and high costs (Helms et al 2005). Recent evidence in clinical studies has further indicated that use of recombinant human bone morphogenetic protein-2 (rhBMP-2) is associated with side effects in the central and peripheral nervous systems (Dmitriev et al 2011).

Casein is a phosphoprotein which accounts for $20 \%$ of the milk protein. It is insoluble in water and thus utilized to prepare organic adhesive. Casein phosphopeptides (CPPs) stabilize the amorphous phase of calcium phosphate (ACP) in solution, and these CPP-ACP complexes have anticariogenic potential (Cross et al 2001; 2004; Shen et al 2001). Casein hydrolysate fraction, when complexed with calcium compounds, help in remineralization of teeth (Huq et al 2003).

The study aims to evaluate the osteoinductive potential of bark extract of TA. Hence, bone implants were prepared using BCP, casein and ethanolic bark extract of TA and its efficacy for inducing new bone formation was analysed in vitro (figure 1). The prepared implant was characterized physicochemically and its in vitro bioactivity was assessed using MG-63 cell line.

\section{Materials and methods}

\subsection{Materials}

TA bark powder was obtained from the Indian Medical Practitioners Cooperative Pharmacy and Stores Limited (IMCOPS), Chennai, India. All other reagents were of analytical grade and used as received. $\beta$ tricalcium phosphate ( $\beta$ TCP) was synthesized by the method of Bow et al (2004). Hydroxyapatite was synthesized by modifying the method of Noorjahan and Sastry (2005).

\subsection{Ethanolic extract of TA}

TA bark powder (50 g) was soaked in 95\% ethanol for 7 days with intermittent shaking and the solvent was filtered with Whatman no. 1 filter paper. The filtrate was evaporated under vacuum drier and the brown residue obtained was stored at $-4{ }^{\circ} \mathrm{C}$ for further use. The brown residue weighed $3.5 \mathrm{~g}$ and the yield was about $7 \%$.

\subsection{Preparation of $\mathrm{BCP}$}

BCP was prepared by physically mixing hydroxyapatite and $\beta$ TCP in the ratio of $60: 40$.

\subsection{Preparation of bone implant with BCP and casein (BC)}

Casein (2 g) was soaked in $6 \mathrm{~mL}$ of $10 \% \mathrm{Ca}(\mathrm{OH})_{2}$ solution. As much as $5 \mathrm{~g}$ of BCP was mixed well with the mixture of casein and calcium hydroxide and a dough was made. This dough was extruded through a glass cylinder $(1 \mathrm{~cm}$ diameter) using a glass rod. The implants were allowed to set at $30{ }^{\circ} \mathrm{C}$ for $24 \mathrm{~h}$ and then cured at $80^{\circ} \mathrm{C}$.

\subsection{Preparation of bone implant with $B C P$, casein and TA extract (BCTA)}

Casein (2 g) was soaked in $6 \mathrm{~mL}$ of $10 \% \mathrm{Ca}(\mathrm{OH})_{2}$ solution. As much as $5 \mathrm{~g}$ of BCP along with $5 \mathrm{mg}$ of TA was 
mixed well with the mixture of casein and calcium hydroxide and a dough was made. This dough was extruded through a glass cylinder (1 cm diameter) using a glass rod. The implants were allowed to set at $30{ }^{\circ} \mathrm{C}$ for $24 \mathrm{~h}$ and then cured at $80{ }^{\circ} \mathrm{C}$.

\subsection{Physicochemical characterization}

2.6a Mechanical properties: Cylindrical specimens (diameter $1 \mathrm{~cm}$, height $0.8 \mathrm{~cm}$ ) of BC and BCTA were prepared and allowed to set at $30^{\circ} \mathrm{C}$ for $24 \mathrm{~h}$ and then cured at $80^{\circ} \mathrm{C}$. To measure the compressive strength, the samples were loaded along the cylindrical axis in between the platens of Instron (4501 model) at a cross-head speed of $1 \mathrm{~mm} / \mathrm{min}$. The compressive strength was calculated from the break load and dimensions of the pellets.

2.6b Fourier transform infrared spectroscopy: Various functional groups present in the prepared and tested samples were identified by FT-IR (Nicolet Magna IR 560, USA). Here, $1 \mathrm{wt} \%$ of the powder was mixed and ground with $99 \% \mathrm{KBr}$. Tablets of $10 \mathrm{~mm}$ diameter were prepared by pressing the powder mixture at a load of 5 tons for $2 \mathrm{~min}$ and the spectrum was taken in the range of $500-4000 \mathrm{~cm}^{-1}$ with resolutions of 4 and 128 times scanning.

2.6c Thermogravimetric analysis: TGA of samples prepared and tested in SBF were carried out using a Seiko SSC $5200 \mathrm{H}$ in nitrogen atmosphere $(80 \mathrm{~mL} / \mathrm{min})$ at a heating rate of $10^{\circ} \mathrm{C} / \mathrm{min}$. Primary weight loss of these materials as a function of temperature was recorded using this study.

2.6d Scanning electron microscopy: Dried samples were coated with an ultra-thin layer of gold using an ion coater (fisons sputter coater) under the following conditions, viz. $0 \cdot 1$ Torr pressure, $200 \mathrm{Ma}$ current and $70 \mathrm{~s}$ coating time. Surface structure was visualized by scanning electron microscope (SEM model LEICA stereoscan 440) using $15 \mathrm{kV}$ accelerating voltage.

2.6e Energy dispersive $X$-ray analysis: For EDX analysis, samples were mounted on holders and $6 \mathrm{~nm}$ sputtercoated with carbon by means of an MED 020 sputter device (Bal-Tec). In a Philips scanning electron microscope (Philips, Eindhoven, the Netherlands), EDX analyses were performed at 5 and $10 \mathrm{kV}$.

\subsection{Biomineralization assay}

2.7a Preparation of simulated body fluid: To investigate bioactivity of biomaterials, SBF was used as growth medium. In SBF, chemical components are similar to the inorganic mineral ions of human blood plasma and of which ion concentrations are also similar to those of human blood plasma. For SBF preparation, pre-determined amounts of reagent-grade $\mathrm{NaCl}, \mathrm{NaHCO}_{3}, \mathrm{KCl}, \mathrm{K}_{2} \mathrm{HPO}_{4}$. $3 \mathrm{H}_{2} \mathrm{O}, \mathrm{MgCl}_{2} \cdot 6 \mathrm{H}_{2} \mathrm{O}, \mathrm{Na}_{2} \mathrm{SO}_{4} \cdot 10 \mathrm{H}_{2} \mathrm{O}$ and $\mathrm{CaCl}_{2} \cdot 2 \mathrm{H}_{2} \mathrm{O}$ were weighed and dissolved in deionized (DI) water. The ionic concentrations in SBF were as follows: $\mathrm{Na}^{+}$ (142 mM), $\mathrm{K}^{+}(5 \mathrm{mM}), \mathrm{Mg}^{2+}(1.5 \mathrm{mM}), \mathrm{Ca}^{2+}(2.5 \mathrm{mM})$, $\mathrm{Cl}^{-}(147 \cdot 8 \mathrm{mM}), \mathrm{HCO}_{3}^{-}(4 \cdot 2 \mathrm{mM}), \mathrm{HPO}_{2}^{4-}$ (1 mM), $\mathrm{SO}_{4}^{2-}$ $(0.5 \mathrm{mM})$, which are nearly equal to those in human blood plasma at $37^{\circ} \mathrm{C}$. SBF was then buffered at $\mathrm{pH} 7 \cdot 4$ with tris(hydroxymethyl) aminomethane and hydrochloric acid at $37^{\circ} \mathrm{C}$.

2.7b In vitro bioactivity test: BC and BCTA implants were well immersed in SBF solution for 21 days. After the specified time intervals, the scaffolds were removed from the SBF solution and washed thrice with DI water to remove adsorbed minerals. BC and BCTA implants tested in SBF were denoted as SBC and SBCTA, respectively. BC, BCTA, SBC and SBCTA were characterized by FT-IR, XRD, TGA, SEM and EDX analyses.

\subsection{Biological assessment}

2.8a Cell culture: The in vitro assay was performed on osteoblast-like cells (MG-63) obtained from National Centre for Cell Science, Pune, India. The cells were grown in Dulbecco's Minimum Eagle's Medium (DMEM) (HiMedia) supplemented with 10\% foetal bovine serum (Gibco Laboratories) and antibiotics (streptomycin, penicillin-G, kanamycin, amphotericin B). About $25 \mu \mathrm{L}$ cell suspension $\left(5 \times 10^{3}\right.$ cells/well) was seeded in each of the 96 wells and incubated at $37^{\circ} \mathrm{C}$ for $48 \mathrm{~h}$ in $5 \% \mathrm{CO}_{2}$ for the formation of a confluent monolayer.

2.8b MTT assay: Cytotoxicity was assessed using MTT [3-(4,5-dimethylthiazol-2-yl)-2,5-diphenyltetrazolium bromide] assay. MG-63 cells were exposed to various concentrations (25, 50, 100 and $200 \mu \mathrm{g}$ ) of BC and BCTA. The cell viability was measured after $96 \mathrm{~h}$ using MTT assay (Carmichael et al 1987). MTT was added at the end of the incubation period and the plates were incubated for $4 \mathrm{~h}$ at $37^{\circ} \mathrm{C}$. Following incubation, the medium was aspirated completely and MTT formazan crystals formed were dissolved by adding DMSO and the absorbance was read at $570 \mathrm{~nm}$ using a multiwell plate reader (Multiskan Ascent VI.24). Controls were maintained throughout the experiment (untreated wells served as cell control). Data were normalized to control to evaluate the effect of the sample BC and BCTA on cells.

2.8c Alkaline phosphatase activity: Alkaline phosphatase (ALP) was measured in culture supernatants as per Pacheco-Pantoja et al (2011). The procedure involves a colorimetric assay using $p$-nitrophenyl phosphate as 
substrate, and measuring $p$-nitrophenol spectrophotometrically released at $405 \mathrm{~nm}$, with the absorbance being proportional to ALP activity. Cells were seeded onto 24-well plates and cultures were treated with $100 \mu \mathrm{g} / \mathrm{mL}$ concentration of BC and BCTA. After different periods of incubation, cell-free supernatants were collected for ALP assay. The determinations were performed using 3 replicates each time. All the treatments were compared against control wells (without treatment).

2.8d Calcium release assay: Alizarin red is used to determine quantitatively the calcium deposition by osteogenic cell lines by colorimetric method. The formation of calcium phosphate by MG-63 osteoblast-like cells was determined as described by using the alizarin red-S assay. The medium was removed, and the cell layers on the matrix were rinsed with phosphate-buffered saline (PBS) three times and fixed in 3.6\% (v/v) formaldehyde at room temperature for $15 \mathrm{~min}$. The fixed cells were stained with $2 \%$ alizarin red $\mathrm{S}(\mathrm{pH} 4 \cdot 1-4 \cdot 3)$ for $15 \mathrm{~min}$ at $25^{\circ} \mathrm{C}$. Then the cell layers were washed with DI water for quantification of staining, $800 \mathrm{~mL}$ of $10 \%(\mathrm{v} / \mathrm{v})$ acetic acid was added to each well and the wells were incubated at room temperature for $30 \mathrm{~min}$ with shaking. The cell layers on the wells were lifted and transferred to a $1.5 \mathrm{~mL}$ micro centrifuge tube. After vortexing for $30 \mathrm{~s}$, the pellet was overlaid with $50 \mu \mathrm{g} / \mathrm{mL}$ mineral oil, heated to $85^{\circ} \mathrm{C}$ for $10 \mathrm{~min}$ and transferred to ice for $5 \mathrm{~min}$. The pellet was centrifuged at $20,000 \mathrm{~g}$ for $15 \mathrm{~min}$ and $50 \mu \mathrm{g} / \mathrm{mL}$ of the supernatant was removed to a new $1.5 \mathrm{~mL}$ micro centrifuge tube. Then, $200 \mu \mathrm{g} / \mathrm{mL}$ of $10 \%(\mathrm{v} / \mathrm{v})$ ammonium hydroxide was added to neutralize the acid. The absorbance of the supernatant was measured at $405 \mathrm{~nm}$ (Gregory et al 2004). Calcium release assay was done on 1st, 7 th and 14th day in triplicates.

\subsection{Statistical analysis}

The data were presented as mean \pm standard deviation (SD) of three individual experiments. The comparison between means of different groups was made by one-way analysis of variance followed by Duncan's multiple range analysis using statistical software package SPSS, version 13. Means bearing different superscripts in a column differed significantly at $p<0 \cdot 05$.

\section{Results and discussion}

\subsection{Physicochemical characterization}

3.1a Compression strength: The bone implants were used to induce new bone formation at the implant site or sometimes implant itself gets ossified thereby filling the gap with new bone. The compression strength of bone implant depends on the particle size, porosity, binding of individual components, nature of the binding material and moisture content present in the sample. The compression strength of $\mathrm{BC}$ was found to be $3.04 \pm 0.13 \mathrm{MPa}$, whereas that of BCTA was $4 \cdot 24 \pm 0 \cdot 18$. After immersion of BC and BCTA implants in SBF for 21 days, the compression strength of SBC and SBCTA implants was found to be $3 \cdot 12 \pm 0.15$ and $4.31 \pm 0.06 \mathrm{MPa}$, respectively. Compression strength of the prepared implants is low for the application as load-bearing implants (10-80 MPa), but significant increase after the addition of TA extract may be due to the cross-linking effects of phenolic groups in TA extract with the functional groups of casein. These implants may be used as osteoinductive materials in the defects of non-load-bearing bone defects.

3.1b FT-IR: IR spectrum of TA (figure 2a) exhibits strong absorption band at $3438 \mathrm{~cm}^{-1}$ representing hydroxyl groups. The vibrational band at $2938 \mathrm{~cm}^{-1}$ was due to the presence of saturated $-\mathrm{C}-\mathrm{H}$ bond. Characteristic bands of carboxylic acid $\left(1716 \mathrm{~cm}^{-1}\right)$, amines (1625 and $1593 \mathrm{~cm}^{-1}$ ) and phenols (1257 and $1171 \mathrm{~cm}^{-1}$ ) are present. Glycosidic linkage represented the peak at $1051 \mathrm{~cm}^{-1}$ (Patnaik et al 2007). IR spectrum of BC (figure 2b) has shown characteristic vibration peaks of phosphate $\left(\mathrm{PO}_{4}^{3-}\right)$ $v_{1}$ and $v_{3}$ at around 961 and $1038 \mathrm{~cm}^{-1}$. Carbonate peaks are identified at 1431 and $875 \mathrm{~cm}^{-1}$. Absorption band at 1676 and $1525 \mathrm{~cm}^{-1}$ represent amides I and II of casein. IR spectrum of BCTA (figure 2c) shows all peaks of BC except amide II peak of casein and amide I peak shifted from 1676 to $1652 \mathrm{~cm}^{-1}$, indicating a reaction between TA extract and functional groups of casein.

\subsection{In vitro bioactivity test}

The biocomposite formed using casein was stable in SBF solution for 21 days. A variety of binding agents like

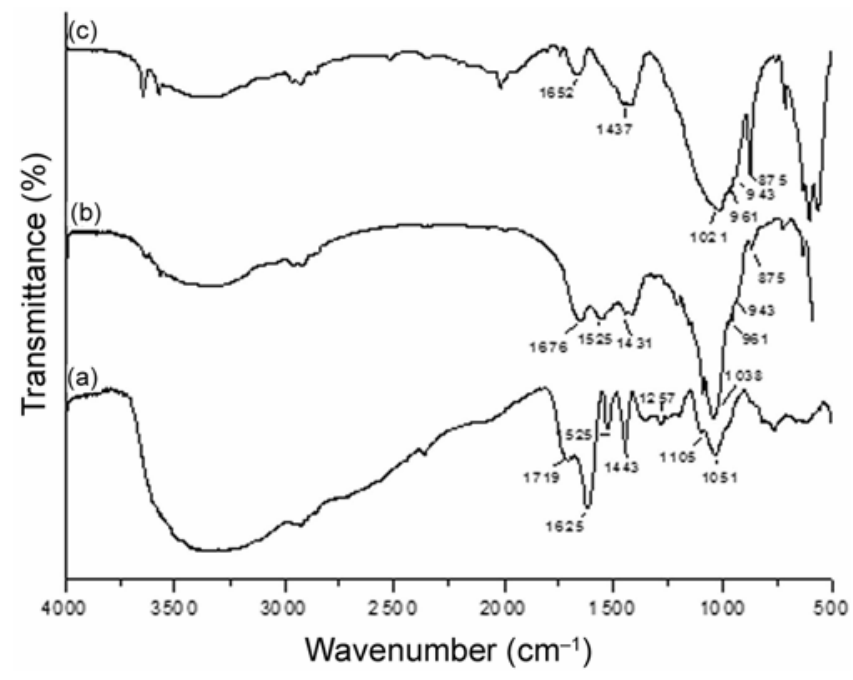

Figure 2. FT-IR spectra of (a) Terminalia arjuna ethanol extract, (b) BC and (c) BCTA. 
gelatin, chitosan and fibrin are employed for preparing bone substitutes, whereas few attempts have been made with casein. In case of gelatin and others, a chemical cross-linking agent is necessary to give stability over a given period of time. Without cross linking, the gelatinbased biocomposite loses its stability in SBF within a day. In this study, casein, a milk protein, was used to prepare BCP biocomposite. Casein, insoluble protein of milk, is rendered soluble by the alkali and then it forms the binder (Silva et al 2003). The stability of the prepared implant is necessary for both in vitro and in vivo bioactivities as it has to be stable at the defective site till it is ossified. Apart from introducing stability to the prepared biocomposite, casein may also be helpful in bone regeneration (James et al 2002).

\section{$3.3 \quad T G A$}

Thermogravimetric analysis reveals loss of weight of the sample with increase in the temperature. This loss may be due to decomposition of sample into carbon dioxide $\left(\mathrm{CO}_{2}\right)$ carbon monooxide $(\mathrm{CO})$ nitrous oxide (NOX) and water vapour. Normally inorganic mineral is stable up to $800{ }^{\circ} \mathrm{C}$. In the present investigation, BC, when subjected to thermal analysis, showed residual weight percentage of $83.22 \%$ at $800{ }^{\circ} \mathrm{C}$. SBC has shown the residual content of $84.77 \%$ under similar conditions. There is a negligible increase of $1.5 \%$ due to the possible ossification. BCTA has shown the residual content of $62 \cdot 89 \%$, whereas the sample SBCTA has shown $77 \cdot 04 \%$ residual content at $800{ }^{\circ} \mathrm{C}$. An increase of $15 \%$ in the inorganic residue shows that BCTA is a good osteoinductive material. The results are shown in figure 3 . The presence of apatite can be confirmed by the increase in residual weight in thermogravimetric analysis for both $\mathrm{BC}$ and BCTA samples. The increase was more in BCTA than in BC and this increase may be attributed to the osteoinductive nature of the TA extract.

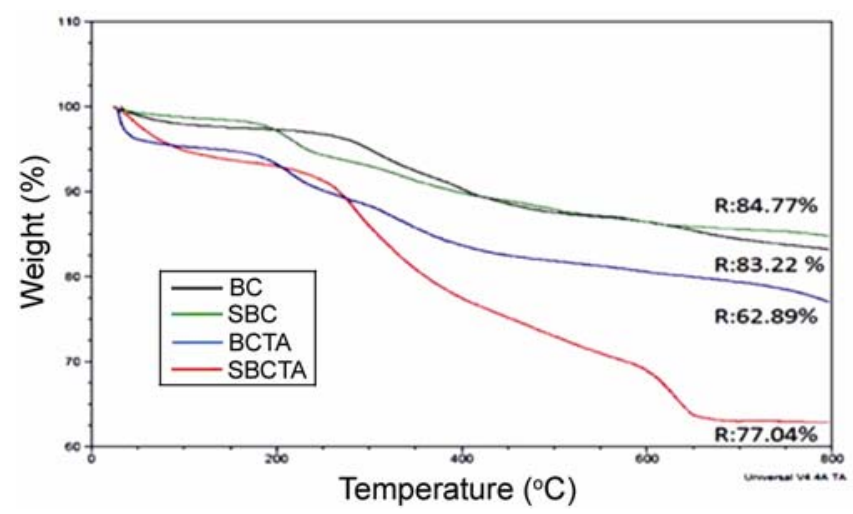

Figure 3. Thermogravimetric analysis of BC, BCTA, SBC and SBCTA.

\subsection{SEM}

Scanning electron micrographs of the samples BC, BCTA, SBC and SBCTA are given in figure 4. In case of $\mathrm{BC}$, crystals are visible in both individual and aggregated forms. In SBC, the surface is modified, the size of individual crystals has increased and it shows possible ossification of the samples. In case of BCTA, crystals appear with a smooth surface, but in SBCTA roughness is observed on the surface of the crystals and there is an increase in size of the individual crystals indicating mineralization. The roughness and increase in size is more prominent in BCTA samples than in BC samples after treatment in SBF. Figure 4(d) clearly depicts the formation of cracks in apatite layers. Ning and Zhou (2002) reported that long periods of immersion would induce formation of cracks in the apatite layers due to drying and shrinkage.

\subsection{EDX}

EDX analysis of the samples is shown in figure 5. In BC and BCTA, calcium level increased up to 2-35- and 4.31fold, respectively, after treatment in SBF, whereas the level of phosphorous increase was about 4.29- and 1.89fold. EDX results reveal the enhancement in the levels of calcium and phosphorus, which may be attributed to the synthesis of hydroxyapatite crystals.

\subsection{Biological assessment}

3.6a MTT assay: The effect of BC and BCTA on cell viability was assessed using MG-63 in order to evaluate their biocompatible nature (figure 6a). More than $85 \%$ viability was observed in all the groups, except at $200 \mu \mathrm{g}$ of BCTA (which was about 76\%). There was no significant difference between BC and BCTA in all concentrations. Both groups showed significant reduction in cell viability at $200 \mu \mathrm{g}$ concentration. As there was no significant difference between BC and BCTA at $200 \mu \mathrm{g}$ concentration, the decrease may be attributed to the increased calcium phosphate content rather than TA extract. Cell inhibitions at higher concentrations of calcium phosphate were well documented in previous studies (Kim et al 2005). Sivalokanathan et al (2006) reported that TA extract inhibited the proliferation of human hepatoma cells (HepG2), osteosarcoma (U2OS), and glioblastoma (U251) cells in a concentration-dependent manner. The study results clearly infer that concentration of TA bark extract used is within the biocompatible range, and it has not inhibited cell proliferation and the observed effect at $200 \mu \mathrm{g}$ could be due to the levels of calcium phosphate. $100 \mu$ g concentration was selected for further studies, viz. alkaline phosphatase assay and calcium release activity assay, since $100 \mu \mathrm{g}$ shows higher cell viability compared with $200 \mu$ g concentration. 


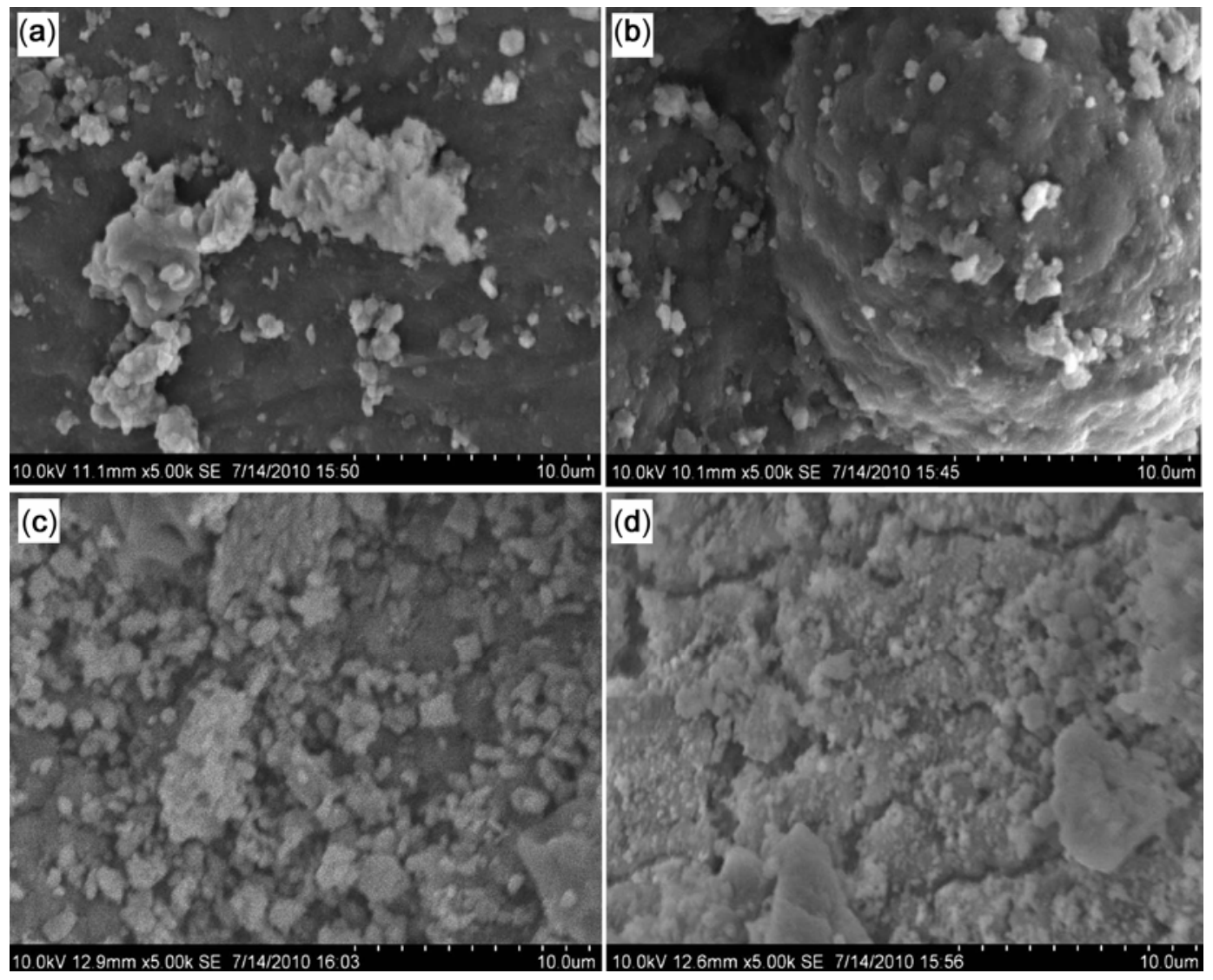

Figure 4. SEM micrograph (magnification 500×) of (a) BC, (b) BCTA, (c) BC after treatment in SBF for 21 days and (d) BCTA after treatment in SBF for 21 days.
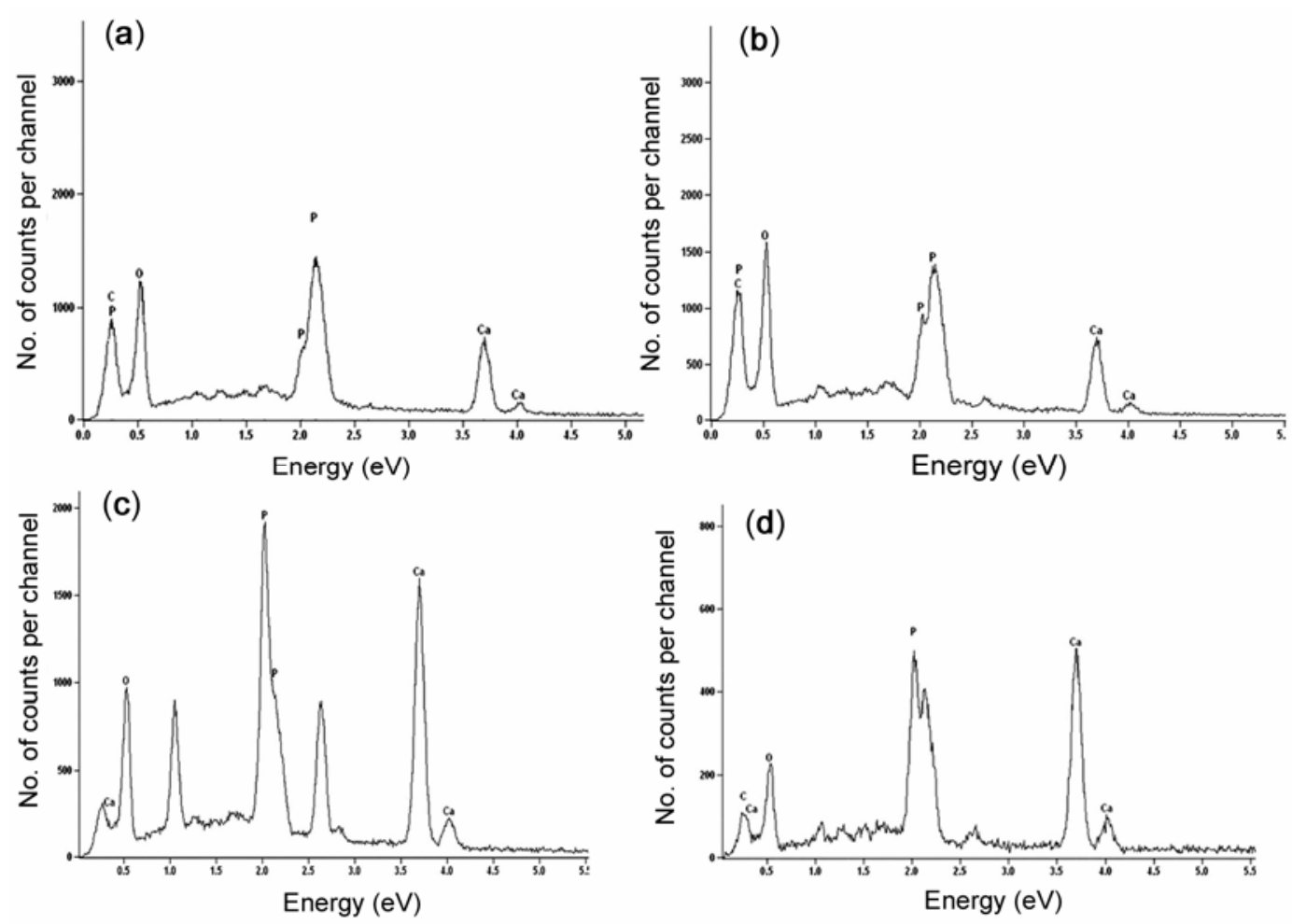

Figure 5. EDX data of (a) BC, (b) BCTA, (c) BC after treatment in SBF for 21 days and (d) BCTA after treatment in SBF for 21 days. 

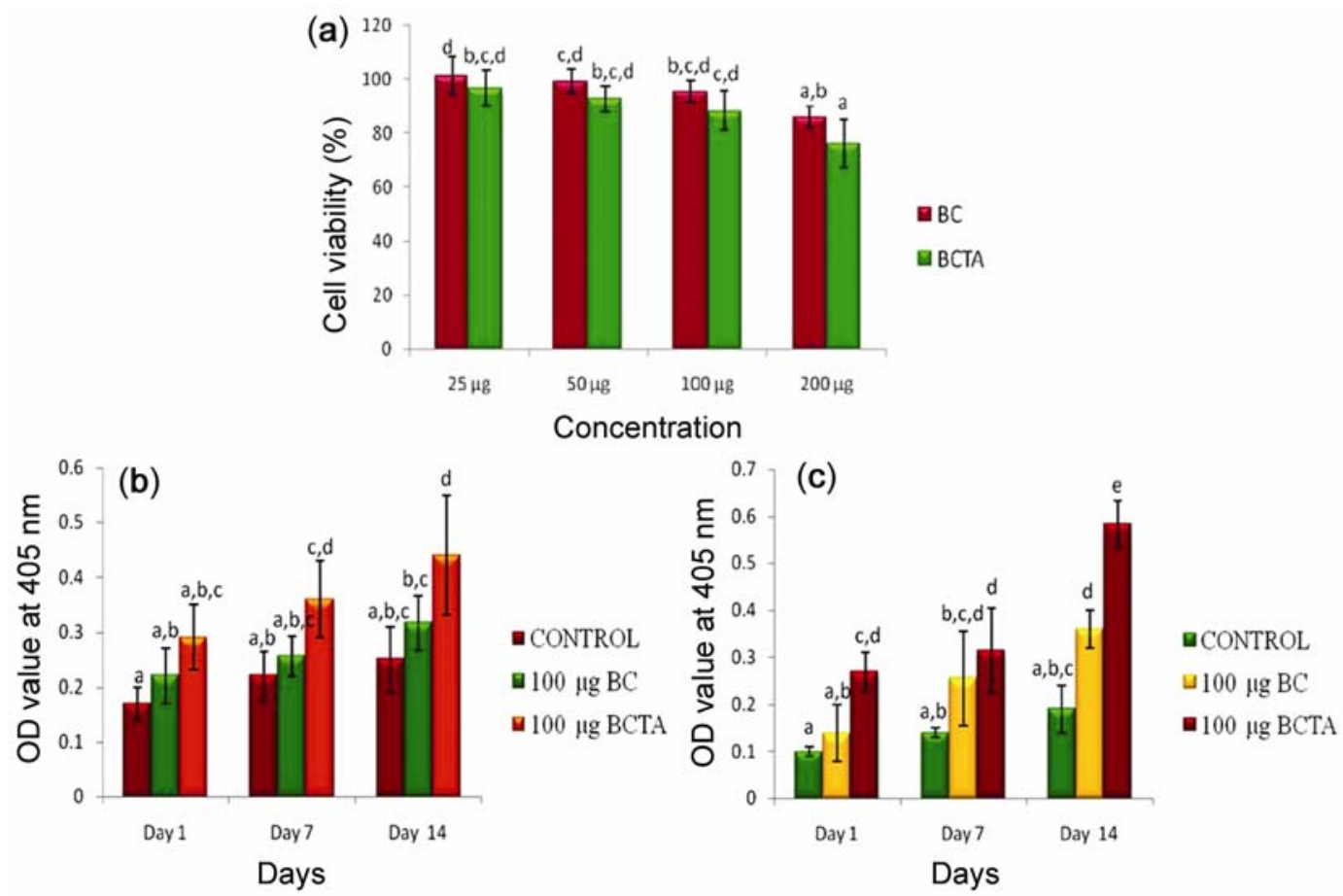

Figure 6. (a) MTT assay. The data are presented as mean \pm SD of three individual experiments. Data were normalized to control. Means bearing different superscripts differed significantly by Duncan's multiple range analysis at $p<0 \cdot 05$. (b) Alkaline phosphatase activity assay. The data are presented as mean \pm SD of three individual experiments. Means bearing different superscripts differed significantly by Duncan's multiple range analysis at $p<0 \cdot 05$. (c) Calcium release assay. The data are presented as mean \pm SD of three individual experiments. Means bearing different superscripts differed significantly by Duncan's multiple range analysis at $p<0 \cdot 05$.

3.6b Alkaline phosphatase (ALP) activity: Alkaline phosphatase is an important marker which is expressed during osteoblastic differentiation (Weinreb et al 1990). At the end of cell proliferation and maturation, cells express higher level of ALP activity. ALP expression levels are an important factor in determining the functions of osteoblast cells. Figure 6(b) reveals the levels of ALP activity expressed by BC and BCTA at $100 \mu$ g concentration on the 1st, 7th and 14th day. On the 1st day there was no significant difference in ALP activity between the groups. On the 7th and 14th days significant increase in ALP activity was observed only in BCTA, but not in BC. This may be due to the influence of TA extract on cell differentiation. Morris (2006) has also reported an increase in ALP activity by soy isoflavones during osteoblastic differentiation in MG-63 cell lines.

3.6c Calcium release assay: Mineralization potential of the cells was quantified by alizarin red assay. The calcium released by BC and BCTA at $100 \mu$ g concentration on various day intervals are given in figure 6(c). There was no significant increase in calcium content in BC up to 7th day and the significant increase was evident on the 14th day. In case of BCTA there was a significant increase in calcium content compared to control throughout the experiment. On the 14th day BCTA showed significant increase in calcium content compared to BC. The significant increase in calcium levels in BCTA may be due to the osteogenic effect of TA extract on MG-63 cells. The increased calcium level and osteogenic differentiation of MG-63 cells on electrospun collagen and electrospun gelatin was earlier reported by Tsai et al (2012).

\section{Conclusions}

The study validates the potential of TA bark extract. Total TA bark extract was used for the study mainly because of the synergistic effect of the phytochemicals on different pathways leading to better bioactivity. Biocomposite prepared using bark extract of TA (BCTA) possessed stability and compression strength. The functional groups of TA extract help in in vitro biomineralization and in MG-63 cells, it showed potential influence on cell differentiation and cell viability. Thus, the prepared biocomposite may be used as potential bone filler in the non-load-bearing areas or as a coating agent in metallic implants to impart bioactivity. With further molecular studies, TA extract might be tried as a possible alternative to BMPs. 


\section{Acknowledgements}

The authors thank Dr A B Mandal, Director, Central Leather Research Institute, Chennai, India, for his kind permission to publish this work. The award of CSIR fellowship to T Hemalatha and DST fellowship to Deepachitra are gratefully acknowledged.

\section{References}

Bow J S, Liou S C and Chen S Y 2004 Biomaterials 253155

Bussmann R W and Sharon D 2006 J. Ethnobiol. Ethnomed. 247

Carmichael J, DeGraff W G, Gazdar A F, Minna J D and Mitchell J B 1987 Cancer Res. 47943

Cross K J, Huq N L, Bicknell W and Reynolds E C 2001 Biochem. J. 356277

Cross K J, Huq N L, Stanton D P, Sum M and Reynolds E C 2004 Biomaterials 255061

Dmitriev A E, Lehman R A and Symes A J 2011 Spine J. 11500

Dwivedi S 2007 Ethnopharmacol 114114

Gauthaman K, Banerjee S K, Dinda A K, Ghosh C C and Maulik S K 2005 J. Ethnopharmacol. 96403

Gregory C A, Gunn W G, Peister A and Prockop D J 2004 Anal. Biochem. 32977

Helms M W, Packeisen J, August C, Schittek B, Boecker W, Brandt B H and Buerger H 2005 J. Pathol. 206366
Hemalatha T, Pulavendran S, Balachandran C, Manohar B M and Puvanakrishnan R 2010 Indian J. Exp. Biol. 48238

Huq N, Cross K J and Reynolds E C 2004 J. Dairy Res. 7128

James P, Sabatier J P, Bureau F, Laroche D, Jauzac P, Arhan P and Bougle D 2002 Nutr. Res. 22385

Kim H W, Knowles J C and Kim H E 2005 J. Biomed. Mater. Res. A72 136

Morris C, Thorpe J, Ambrosio L and Santin M 2006 J. Nutr. 1361166

Ning C Q and Zhou Y 2002 Biomaterials 232909

Noorjahan S E and Sastry T P 2005 J. Biomed. Mater Res. B Appl. Biomater. B75 343

Ogose A, Hotta T, Kawashima H, Knodo N, Gu W G, Kamura T and Endo N 2005 J. Biomed. Mater. Res. B Appl. Biom. B72 94

Pacheco-Pantoja E L, Ranganath L R, Gallagher J A, Wilson P J and Fraser W D 2011 BMC Physiol. 1112

Patnaik T, Dey R K and Gouda P 2007 E-J. Chem. 4474

Raskin I and Ripoll C 2004 Curr. Pharm. Des. 103419

Shen P, Cai F, Nowicki A, Vincent J and Reynolds E C 2001 J. Dent. Res. 802066

Silva G A, Vaz C M, Coutinho O P, Cunha A M and Reis R L 2003 J. Mater. Sci. Mater. Med. 141055

Sivalokanathan S, Vijayababu M R and Balasubramanian M P 2006 World J. Gastroenterol. 121018

Tsai S W, Liou H M, Lin C J, Kuo K L, Hung Y S, Weng R C and Hsu F Y 2012 PLoS One 7 e31200

Weinreb M, Shinar D and Rodan G A 1990 J. Bone Miner. Res. 5831 